\title{
Inheritance of cytosine methylation patterns in purebred versus hybrid chicken lines
}

\author{
Q. Xu' ${ }^{2}$, D.X. Sun ${ }^{1}$, J.L. Li ${ }^{2}$, R. Liu ${ }^{1}$, Y.C. Wang ${ }^{1}$ and Y. Zhang ${ }^{1}$ \\ ${ }^{1}$ Key Laboratory of Agricultural Animal Genetics and Breeding, \\ National Engineering Laboratory for Animal Breeding, \\ College of Animal Science and Technology, \\ China Agricultural University, Beijing, China \\ ${ }^{2}$ Institute of Life Science and Biotechnology, \\ Beijing Jiaotong University, Beijing, China \\ Corresponding author: Q. Xu \\ E-mail: qingxu@bjtu.edu.cn
}

Genet. Mol. Res. 12 (3): 2674-2687 (2013)

Received August 30, 2012

Accepted March 20, 2013

Published July 30, 2013

DOI http://dx.doi.org/10.4238/2013.July.30.6

\begin{abstract}
We used methylation-sensitive amplified polymorphism to examine DNA methylation levels and CCGG patterns in parents and offsprings of 3 groups of adult chickens, purebred White Leghorn (AA), White Plymouth Rock (EE), and crossbred individuals (EA) using 10 primer combinations. We found that about $66 \%$ of the cytosines at CCGG sites were not methylated. Fully methylated sites were less frequent than hemi-methylated sites in the chicken genome; these frequencies were different from those of plants. We observed that the probability that the offspring would inherit the methylation pattern for any given site from the parents was $88 \%$; consequently, unexpected methylation patterns in offspring occurred at a rate of about $12 \%$. The methylation degree in offspring was lower than in parents, and there were more sites with altered methylation patterns in EA crossbreds compared with AA and EE purebreds. Seven differentially methylated fragments between parental lines and their offspring were isolated, sequenced, and characterized, 4 of which were located in the coding
\end{abstract}


regions. We conclude that most of the methylation status is transferred from parents to offspring in chickens, and that there are differences in the inheritance of methylation status in purebred versus crossbred offspring. We also concluded that methylation-sensitive amplified polymorphism is highly efficient for large-scale detection of cytosine methylation in the chicken genome.

Key words: Chicken, Methylation pattern, MSAP, Blood genome

\section{INTRODUCTION}

The methylation of DNA is one of main epigenetic modification patterns in many eukaryotic organisms and plays an important role in diverse biological processes such as embryogenesis, genomic imprinting, cell differentiation, and chromatin inactivation, as well as cancer (Vanyushin, 2005; Gopalakrishnan et al., 2008; Kurkjian et al., 2008). Mapping of methylation patterns at $\mathrm{CpG}$ sites has become an important tool for understanding both normal and pathologic gene expression events. In recent years, considerable attention has been paid to studies of DNA methylation in the area of animal genetics and breeding. Significant differences in levels or patterns of cytosine methylation have been found in various tissue types in some domestic animals such as chickens (Mandel and Chambon, 1979; Xu et al., 2011) and swine (Yang et al., 2011). In addition, another study provided epigenetic evidence for functionally relevant methylation differences between different tissues ( $\mathrm{Li}$ et al., 2012). Meanwhile, DNA methylation is also involved in the development process of animals (Feng et al., 2010). In sheep, high cell proliferation rates, changes in global methylation, and mRNA expression of factors have been shown to be involved in the regulation of DNA methylation and angiogenesis in fetal membranes during early pregnancy (Grazul-Bilska et al., 2011). Also, DNA methylation changes have been found to be related to the migration of primordial germ cells in pigs (Hyldig et al., 2011).

Detection methods for DNA methylation have improved with the study of methylation. The classical method of analyzing methylation combines restriction enzyme digestion and Southern hybridization, based on the property of some restriction enzymes not cutting methylated DNA. In principle, this method can detect the methylation status of $\mathrm{CpG}$ islands, but requires a large amount of DNA and high degree of methylation in the genome (Bird and Taggart, 1980). The bisulfite method overcomes some weaknesses in the restriction method by using sodium bisulfite to convert all unmethylated but not methylated cytosines to uracil to facilitate the detection of methylation. This requires only small quantities of DNA, but prior knowledge of the genomic sequence is needed (Herman et al., 1996). Recently, developed methods for detecting methylation based on microarray (Sato et al., 2003), pyrosequencing (Tost et al., 2003), and ChIP-on-chip (Keshet et al., 2006) can satisfy high-resolution requirements, but they are mainly used in specialized research such as cancer with sophisticated equipment and high cost (Shames et al., 2007). Moreover, like all high-content screening approaches, the huge amounts of data from these methods must be interpreted carefully and independently confirmed by other methods. Compared to other methods, methylation-sensitive amplified polymorphism (MSAP) based on restriction enzyme and PCR amplification is relatively more sensitive, simpler, faster, and cheaper for investigating global methylation patterns 
of cytosines in the whole genome and does not require any prior information of nucleotide sequence (Xiong et al., 1999).

The aim of this study was to profile the cytosine methylation at CCGG sites and to characterize the methylation patterns in parents and offspring from 3 crossed groups of adult chickens using the MSAP method. We found that most of the methylation status is transferred from parents to offspring in chickens, even though differences exist when the methylation status is passed to purebred or crossbred offspring. Our results again demonstrate that MSAP is highly efficient for the detection of cytosine methylation in chickens, especially in understanding the molecular basis of heterosis.

\section{MATERIAL AND METHODS}

\section{Animal materials and DNA extraction}

The White Leghorn (AA, Waalwijk and Flavell, 1978), White Plymouth Rock (EE), and their offspring $\left(\mathrm{F}_{1 \mathrm{AA}}, \mathrm{F}_{1 \mathrm{EE}}\right.$, and $\left.\mathrm{F}_{1 \mathrm{EA}}\right)$ across 3 groups were used in the experiment to detect the patterns of cytosine methylation. Genomic DNA was extracted from blood samples of 42 experimental animals using the QIAmp DNA mini-kit as directed by manufacturer instructions (Qiagen, Valencia, CA, USA) and subsequently quantified using a spectrophotometer. More detailed information on the number and group of chickens used in the current study is presented in Table 1.

Table 1. Experimental design and definition of animal groups.

\begin{tabular}{|c|c|c|c|c|c|c|c|c|c|}
\hline & \multicolumn{3}{|c|}{ Group 1} & \multicolumn{3}{|c|}{ Group 2} & \multicolumn{3}{|c|}{ Group 3} \\
\hline & $\mathrm{AA}(+9)$ & $\mathrm{AA}\left(\delta^{\circledR}\right)$ & $\mathrm{F}_{1 \mathrm{AA}}$ & $\mathrm{EE}(+)$ & $\mathrm{EE}\left({ }_{0}\right)$ & $F_{1 E E}$ & $\mathrm{AA}(\mathrm{Q})$ & $\mathrm{EE}\left(ठ^{\star}\right)$ & $\mathrm{F}_{1 \mathrm{EA}}$ \\
\hline Line 1 & 1 & 1 & 5 & 1 & 1 & 5 & 1 & 1 & 5 \\
\hline Line 2 & 1 & 1 & 5 & 1 & 1 & 5 & 1 & 1 & 5 \\
\hline
\end{tabular}

Groups 1 and 2 = purebred parents and their 5 offspring of White Leghon (AA, Waalwijk and Flavell, 1978) and White Plymouth Rock (EE), respectively. Group $3 \mathrm{~F}_{1 \mathrm{EA}}=5$ crossbred offspring resulted from dam breed AA and sire breed EE; all $\mathrm{F}_{1}$ animals are randomly selected full sibs. Lines 1 and 2 = animals of same breed, however, genetically not related.

\section{Primers, adapters, and MSAP analysis}

The cytosine methylation patterns of blood were investigated by MSAP, in which, isoschizomers HpaII and MspI, recognizing the same sequences but differing in their sensitivities to methylation of their recognition site, were used to digest the genomic DNA followed by ligation to adaptors and selective amplification, and methylation-sensitive polymorphic fragments were then generated. The MSAP system consists of 4 major parts, namely restriction, ligation, amplification, and detection reactions. Adapters and primers were designed according to Xu et al. (2000), with some modifications (see Table 2).

\section{Restriction reactions}

Two digestion reactions (EcoRI/MspI and EcoRI/HpaII) were carried out simultaneously. In the $E c o \mathrm{RI} / M s p \mathrm{I}$ reaction, $5 \mu \mathrm{g}$ chicken genomic DNA was digested for $6 \mathrm{~h}$ in a water bath at $37^{\circ} \mathrm{C}$ with $2 \mu \mathrm{L}$ EcoRI/MspI, $5 \mu \mathrm{L} 10 \mathrm{X}$ B buffer, $1 \mu \mathrm{L}$ BSA, and $30 \mu \mathrm{L}$ sterile 
distilled $\mathrm{H}_{2} \mathrm{O}$. In the EcoRI/HpaII reaction, the same amount of chicken genomic DNA was digested with EcoRI/HpaII under the same reaction conditions. Restriction enzymes EcoRI, MspI, HpaII, and BSA, B buffer were purchased from Promega.

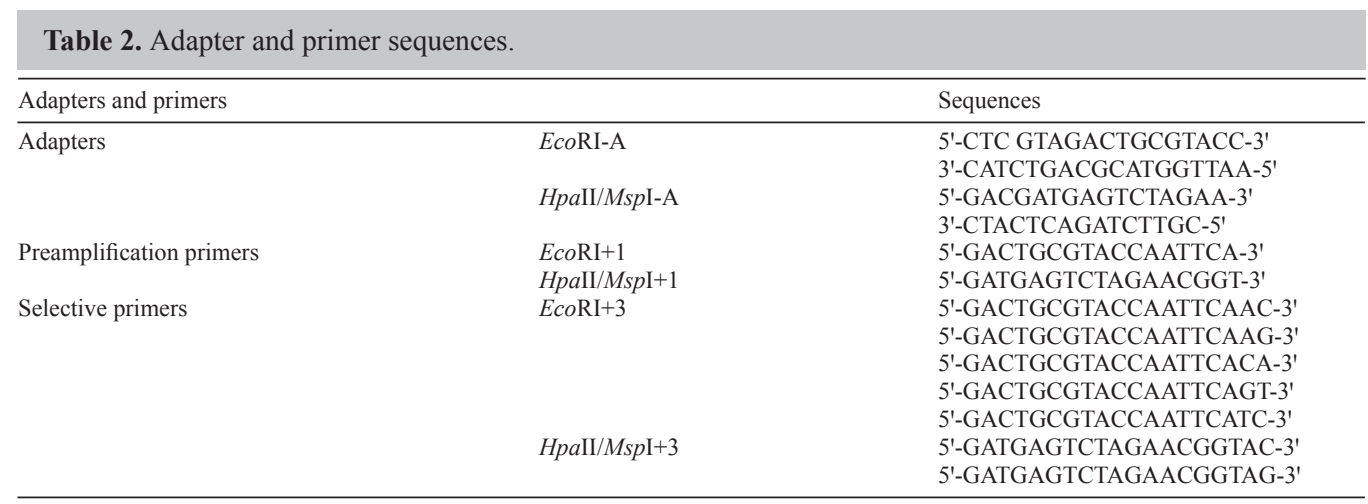

\section{Ligation reactions}

The digested DNA fragments from 2 digestion reactions were ligated to adaptors separately with an equal volume of ligation solution. The ligation reaction of $50 \mu \mathrm{L}$ containing $12.5 \mu \mathrm{L}$ digested products, $50 \mathrm{pM}$ H-M-adapter, $5 \mathrm{pM}$ E-adapter, $3 \mu \mathrm{L}$ T4 DNA ligase, $5 \mu \mathrm{L}$ $10 \mathrm{X}$ buffer, and $24 \mu \mathrm{L}$ sterile distilled $\mathrm{H}_{2} \mathrm{O}$ was carried out at $16^{\circ} \mathrm{C}$ overnight, subsequently denatured for $8 \mathrm{~min}$ at $65^{\circ} \mathrm{C}$, then cooled to room temperature, and finally stored at $-20^{\circ} \mathrm{C}$. T4 DNA ligase and 10X T4 DNA ligase buffer were purchased from TaKaRa.

\section{Preamplification}

PCR was performed in a final volume of $20 \mu \mathrm{L}$ and the solution contained $0.5 \mu \mathrm{L}$ ligation products, $30 \mathrm{ng} \mathrm{H}-\mathrm{M}+1$ primer, $30 \mathrm{ng} \mathrm{E}+1$ primer, $0.1 \mu \mathrm{L}$ Ex Taq polymerase, 1.6 $\mu \mathrm{L}$ dNTPs (2.5 mM each), $1.2 \mu \mathrm{L} 25 \mathrm{mM} \mathrm{MgCl}, 2 \mu \mathrm{L} 10 \mathrm{X}$ PCR buffer, and $14.1 \mu \mathrm{L}$ sterile distilled $\mathrm{H}_{2} \mathrm{O}$. The PCR conditions were as follows: $94^{\circ} \mathrm{C}$ for $5 \mathrm{~min} ; 30$ cycles of $94^{\circ} \mathrm{C}$ for $30 \mathrm{~s}$, $56^{\circ} \mathrm{C}$ for $1 \mathrm{~min}$, and $72^{\circ} \mathrm{C}$ for $1 \mathrm{~min}$; and a final extension at $72^{\circ} \mathrm{C}$ for $7 \mathrm{~min}$. Ex Taq polymerase, dNTP mixture, $\mathrm{MgCl}_{2}$, and Ex Taq polymerase buffer were purchased from TaKaRa.

\section{Selective amplification}

The selective PCR was performed in a $20-\mu \mathrm{L}$ reaction volume containing $0.2 \mu \mathrm{L}$ preamplification products, $30 \mathrm{ng} \mathrm{H}-\mathrm{M}+3$ primer, $5 \mathrm{ng} \mathrm{E}+3$ primer, $0.1 \mu \mathrm{L}$ Ex Taq polymerase, 1.6 $\mu \mathrm{L}$ dNTPs (2.5 mM each), $1.2 \mu \mathrm{L} 25 \mathrm{mM} \mathrm{MgCl}, 2 \mu \mathrm{L} 10 \mathrm{X}$ PCR buffer, and $14.1 \mu \mathrm{L}$ sterile distilled $\mathrm{H}_{2} \mathrm{O}$. The PCR conditions were as follows: $94^{\circ} \mathrm{C}$ for $5 \mathrm{~min} ; 13$ touchdown cycles of $94^{\circ} \mathrm{C}$ for $30 \mathrm{~s}, 65^{\circ} \mathrm{C}$ (subsequently reducing each cycle by $0.7^{\circ} \mathrm{C}$ ) for $30 \mathrm{~s} ; 72^{\circ} \mathrm{C}$ for $1 \mathrm{~min}$; 23 continued cycles of $94^{\circ} \mathrm{C}$ for $30 \mathrm{~s}, 56^{\circ} \mathrm{C}$ for $30 \mathrm{~s} ; 72^{\circ} \mathrm{C}$ for $1 \mathrm{~min}$; and a final extension at $72^{\circ} \mathrm{C}$ for $7 \mathrm{~min}$. Ex Taq polymerase, dNTP mixture, $\mathrm{MgCl}_{2}$ and Ex Taq polymerase buffer were purchased from TaKaRa. 


\section{Detection assay}

Five microliters of selective amplified products mixed 1:1 (v/v) with loading buffer was heated at $95^{\circ} \mathrm{C}$ for $5 \mathrm{~min}$ and quick-chilled on ice. The entire mixture was loaded onto a $4.5 \%$ denaturing polyacrylamide gel. The electrophoresis was performed at constant power of $75 \mathrm{~W}$ for $1.5 \mathrm{~h}$. After detection by silver staining, statistical analysis was carried out.

\section{Isolation of the specific fragment}

To isolate the fragments of interest, the final selective amplification products containing tissue-specific fragment related to methylation were denatured, separated on a Long Ranger, and visualized by silver staining. The fragments were then excised from the gel, reamplified using the PCR conditions as used in the selective amplification and purified with the BioGene Geneclean III kit (Carlsbad, CA, USA). The purified productions were cloned into PMD18 T-vector (Takara, Japan). Escherichia coli competent cells were transformed with the recombinant plasmid and selected by the ampicillin-white/blue colony screen. Positive colonies of each marker were confirmed by PCR using selective primers. Individual clones were sequenced using M13 universal primers. For each tissue-specific fragment, at least 3 sequences were obtained.

\section{Southern blot}

After digestion of a 50- $\mu \mathrm{g}$ high molecular mass DNA from each tissue with HpaII$E c o$ RI and MspI-EcoRI, the products were electrophoresed on a $0.8 \%$ agarose gel in TBE and then transferred to Hybond-N+ (Promega). Probe labeling, membrane transfer and fixation, hybridization, and immunological detection were carried out according to the instructions of DIG High Prime DNA Labeling and Detection Starter kit 1 (Roche Applied Sciences, Mannheim, Germany). The probe was generated by PCR amplification of plasmid DNA from the positive colonies obtained above. The PCR amplification system was the same as that in the preamplification.

\section{DNA sequencing and sequence analysis}

Recombinant clones containing tissue-specific fragments were sequenced with the ABI 3700 Genetic Analyzer (Applied Biosystems). Analysis of DNA similarity was performed by the BLASTn program at the National Center for Biotechnology Information website (www. ncbi.nlm.nih.gov).

\section{RESULTS}

\section{Cytosine methylation profiles of individual chicken genome}

The difference in cytosine methylation patterns at the CCGG sites (a sequence that is recognized by HpaII/MspI and is a prominent site for methylation modification in eukaryotes) within genomes causes differential digestion of their genomic DNA by the methylation-sensi- 
tive isoschizomers, HpaII and MspI. The epigenetic difference can be revealed by the MSAP method when the genomic DNA is digested and then used as template for genome-wide amplification analysis, provided that the CCGG site(s) is internal in the amplified fragments. In this study, each individual genome displayed 10-20 clear bands between 50 and $2000 \mathrm{bp}$ with each primer combination. In particular, as shown in Figure 1, fragments between 100 and $500 \mathrm{bp}$ were highly intense and there were relatively fewer fragments exceeding $1000 \mathrm{bp}$. Typically, the MSAP bands could be grouped into 3 types with the methylation status as follows (Table 3 and Figure 2): type I shows bands of the same length present in both lanes, which implies that no DNA methylation events occurred at this site; type II shows the unique band only in the $\mathrm{M}(M s p \mathrm{I} / E c o \mathrm{RI})$ lane, which implies a full methylation of the internal cytosine in the CCGG sequence; and type III shows the unique band only in the $\mathrm{H}$ (HpaII/EcoRI) lane, which implies a hemi-methylation at the external cytosine nucleotide in the CCGG sequence. In all the samples examined, as indicated in Table 4, type I was the most frequently observed, representing about $66.1 \%$ of the total occasions, while the sum of types II and III, indicating the methylated fragments, accounted for about $33.9 \%$; on average type II bands (fully methylation of cytosines) comprised $44.5 \%$ of the total methylated bands (type II + type III). These results showed that hemi-methylation of external cytosine occurred more often than fully methylated types at CCGG sites in the chicken genome.

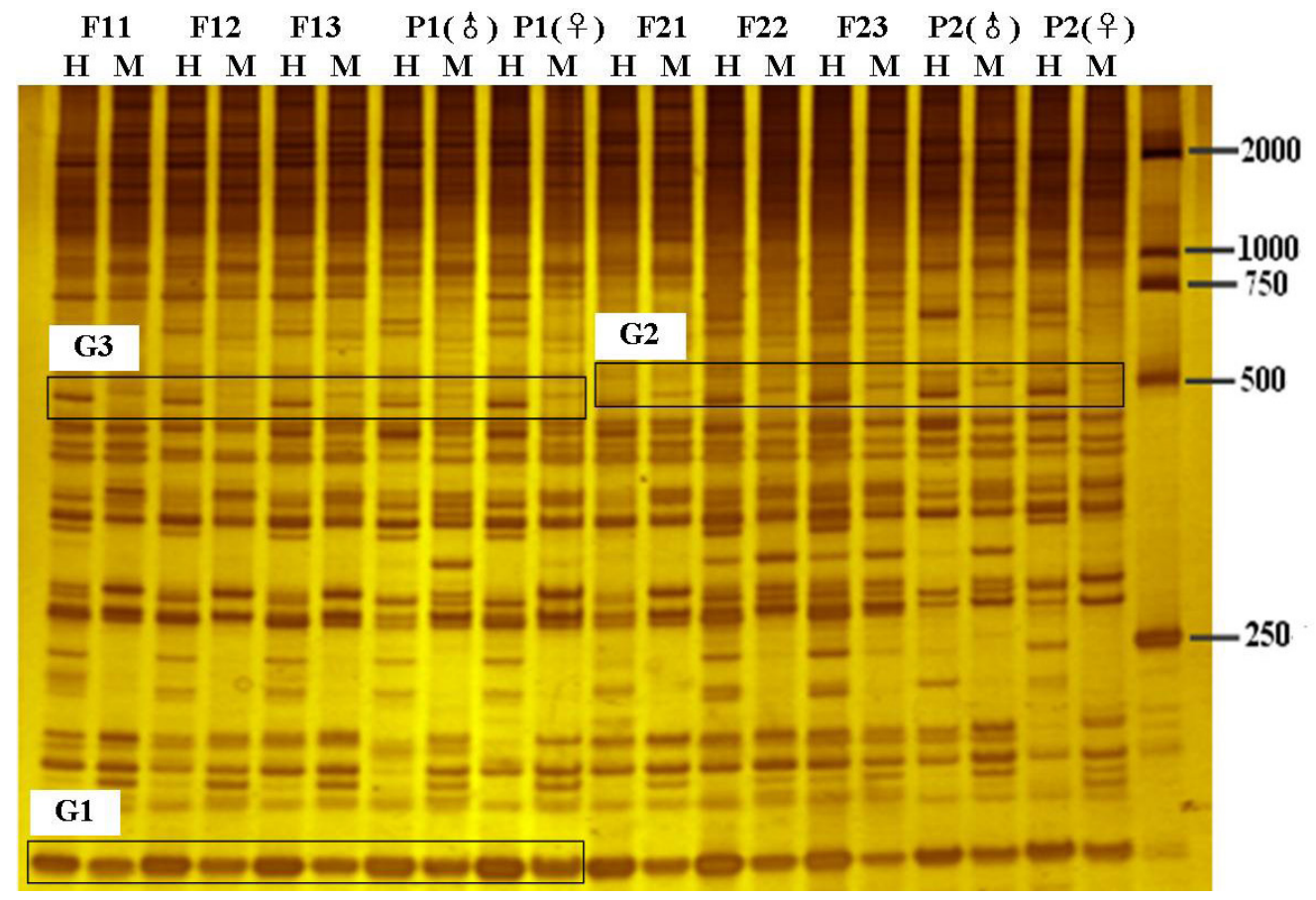

Figure 1. Examples of methylation patterns detected in chicken parents and their offspring by methylation-sensitive amplified polymorphism. The primer combination used was $\mathrm{H}-\mathrm{M}+\mathrm{TAC} / \mathrm{E}+\mathrm{ACA}$. Lanes $F 11$ to $P 2($ P $)=$ offspring (F11, F12, F13, F21, F22, and F23), parents of breed White Leghon [P1 (ð), P2 (ð)], and White Plymouth Rock [P1 (+), P2 (+)], respectively. $\mathrm{H}$ and $\mathrm{M}=$ digestion with EcoRI/HpaII and EcoRI/MspI, respectively. G1, G2, and $\mathrm{G} 3$ = 3 main patterns that offspring fully inherited methylation pattern from their parents. See also Table 5. 
Table 3. Methylation sensitivity and restriction pattern of isoschizomers.

\begin{tabular}{|c|c|c|c|c|c|}
\hline \multirow[t]{2}{*}{ Type } & \multirow[t]{2}{*}{ Methylation status* } & \multicolumn{4}{|c|}{ Digestibility of enzyme restriction pattern } \\
\hline & & HpaII & MspI & $\mathrm{H}^{* *}$ & $M^{* *}$ \\
\hline \multirow[t]{2}{*}{ Type I } & \begin{tabular}{|l|l|l|l|} 
& & & \\
\end{tabular} & & & & \\
\hline & site of no methylation & Active & Active & 1 & 1 \\
\hline \multirow[t]{2}{*}{ Type II } & \begin{tabular}{|l|l|l|} 
&
\end{tabular} & & & & \\
\hline & site of full methylation & Active & Inactive & 0 & 1 \\
\hline \multirow[t]{2}{*}{ Type III } & \begin{tabular}{l|l|l|}
$\square$ & & \\
\end{tabular} & & & & \\
\hline & site of hemi-methylation & Inactive & Inactive & 1 & 0 \\
\hline
\end{tabular}

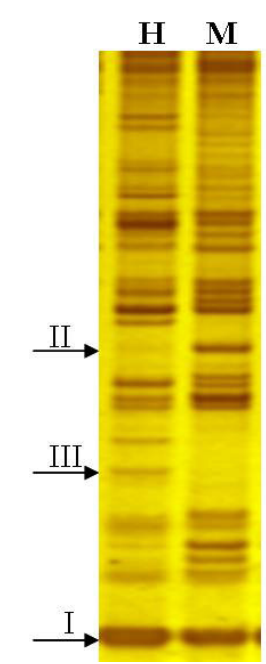

Figure 2. Cytosine methylation patterns with the primer combination of H-M + TAC/E + ACA by methylationsensitive amplified polymorphism. $\mathrm{H}$ and $\mathrm{M}$ refer to digestion with $E c o \mathrm{RI} / H p a \mathrm{II}$ and $E c o \mathrm{RI} / M s p \mathrm{I}$, respectively. Arrows at positions I, II, and III refer to site of no methylation, hemi-methylation, and full methylation, respectively. See also Table 3.

Table 4. Degree of methylation in genomes of parental chicken lines and their offspring $\left(\mathrm{F}_{1}\right)$ lines.

\begin{tabular}{|c|c|c|c|c|c|c|c|c|c|}
\hline \multirow[t]{2}{*}{ Types } & \multicolumn{3}{|c|}{$\begin{array}{l}\text { White Leghorn } \\
\quad \text { (group 1) }\end{array}$} & \multicolumn{3}{|c|}{$\begin{array}{l}\text { White Plymouth Rock } \\
\text { (group 2) }\end{array}$} & \multicolumn{3}{|c|}{$\begin{array}{l}\text { White Leghorn/White Plymouth Rock } \\
\text { (group 3) }\end{array}$} \\
\hline & $\mathrm{AA}(+9)$ & $\mathrm{AA}\left(0^{\pi}\right)$ & $\mathrm{F}_{1 \mathrm{AA}}$ & $\mathrm{EE}(q)$ & $\mathrm{EE}(\precsim)$ & $\mathrm{F}_{1 \mathrm{EE}}$ & $\mathrm{AA}(+)$ & $\mathrm{EE}($ ठ) & $\mathrm{F}_{1 \mathrm{EA}}$ \\
\hline Total amplified bands & 112 & 114 & 113 & 129 & 116 & 100 & 137 & 131 & 126 \\
\hline Total methylated bands ${ }^{\mathrm{a}}$ & 40 & 40 & 40 & 45 & 38 & 34 & 45 & 45 & 40 \\
\hline Methylation level $(\%)^{\mathrm{b}}$ & 35.7 & 35.1 & 35.4 & 34.9 & 32.8 & 34.0 & 32.8 & 34.4 & 31.7 \\
\hline Type II & 19 & 15 & 17 & 21 & 18 & 16 & 18 & 20 & 19 \\
\hline Type II $(\%)^{\mathrm{c}}$ & 17.0 & 13.2 & 15.0 & 16.3 & 15.5 & 16.0 & 13.1 & 15.3 & 15.0 \\
\hline Type III & 21 & 25 & 23 & 24 & 20 & 18 & 27 & 25 & 21 \\
\hline Type III $(\%)^{d}$ & 18.7 & 21.9 & 20.4 & 18.6 & 17.3 & 18.0 & 19.7 & 19.1 & 16.7 \\
\hline
\end{tabular}

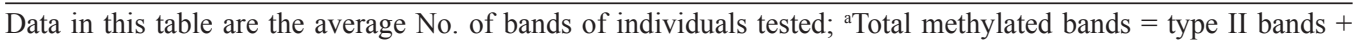
type III bands; ${ }^{b}$ Methylation level $(\%)=$ number of (type II + type III) bands/number of (type I + type II + type III) bands; ${ }^{\mathrm{C}}$ Type II $(\%)=$ number of type II bands/number of (type I + type II + type III) bands; ${ }^{\mathrm{d}}$ Type III $(\%)=$ number of type III bands/number of (type I + type II + type III) bands. 


\section{Methylation levels of parental lines and their offspring in 3 groups}

We used 10 pairs of selective primers from five EcoRI primers in combination with two HpaII/MspI primers to detect cytosine methylation at CCGG sites of various samples from 3 groups. Ten pairs of selective primers produced a total of 1078 clear bands including type I, type II, and type III in 3 groups from 42 chickens (Table 4). The total methylation level of genome for each individual was assessed with the ratio of methylated bands (type II + type III) to the number of all the bands (type I + type II + type III). On average, 35.7, 35.1, and $35.4 \%$ of the CCGG sites in the genome of 2 parental lines and their offspring were cytosine-methylated, respectively, in group 1 (AA inbred line), $34.9,32.8$, and $34.0 \%$ in group 2 (EE inbred line), and $32.8,34.4$, and $31.7 \%$ in group 3 (EA crossbred line), respectively (Table 4). When comparing the total methylation level of parents to their offspring across 3 groups, in purebred lines (group 1 and group 2), the total methylation level of offspring was close to that of their parents, while in crossbred line (group 3), the total methylation level of offspring was $5.7 \%$ less than that of their parents, possibly due to less hemi-methylation in the offspring of group 3 compared to that of their parents (Table 4). Also, this result may indicate that decreased methylation had taken place in some sites of EA hybrids.

\section{Methylation patterns of 2 parental lines and their offspring}

The DNA methylation patterns of CCGG sites were screened among parents and offspring of chicken across 3 groups. Two major patterns were found among the MSAP fragments (Table 5): 1) Inherited pattern (class G). The methylation patterns of offspring were in accordance with those in either or both parental lines. In the current study, the ratio of the offspring inheriting the methylation from both parents for any given site was approximately $56.1 \%$, and that from either parents was approximately $31.8 \%$ (usually, one of the parents was methylated at the internal cytosine and the other parent was methylated at the external cytosine or both in this pattern; data not shown). For the inheritance pattern G1 (the most abundant pattern in class G), 53, 54, and 46 fragments detected by 10 primer pairs implied no methylation in CCGG sites in the 3 groups, respectively (Table 5, Figure 1). The highest frequency of sites with pattern G1 across the 3 groups (45.3, 46.2 , and $34.9 \%$, respectively, for groups 1,2 , and 3 ) hinted that most of CCGG sites in the chicken genome would be non-methylated. 2) Altered pattern. The appearance of a different methylation pattern in offspring when compared to its parental lines was considered as an alteration. The possibility of sites in this pattern was about $12 \%$ across the 3 groups, including 6 increased (class I) and 5 decreased (class D) methylation patterns in the current study (Table 5 shows only patterns with high frequencies). The 5 patterns in class D represented a decrease in the level of methylation in the offspring compared to the parents. As shown in Table 5, more fragments were detected in classes D1 and D2, in which fully methylated or hemi-methylated bands appeared in 1 or 2 parental lines but with no methylation event detected in their offspring. This indicates that de-methylation had occurred at those sites in the offspring. In contrast to class D, increased methylation events (class I, Table 5) were detected in the offspring compared with their parental lines, and classes I1 and I 2 were the most representative of this pattern. When consider- 
ing the frequencies of altered sites in purebred lines and crossbred line, an obviously higher frequency was found in group $3(18.2 \%)$ than in groups $1(7.7 \%)$ and $2(9.4 \%)$. The interesting coincidence of the lower degree of methylation and higher incidence of altered pattern of methylation in hybrid individual may provide hints for further research on genetic mechanism of heterosis.

\begin{tabular}{|c|c|c|c|c|c|c|c|c|c|}
\hline \multirow[t]{2}{*}{ Pattern $^{a}$} & \multicolumn{2}{|c|}{ Parental lines $(+)$} & \multicolumn{2}{|c|}{ Parental lines $(\widehat{\jmath})$} & \multicolumn{2}{|c|}{$\mathrm{F}_{1}$} & \multicolumn{3}{|c|}{ Number of sites ${ }^{\mathrm{g}}$} \\
\hline & $\mathrm{H}^{\mathrm{b}}$ & $\mathrm{M}^{\mathrm{b}}$ & $\mathrm{H}$ & $\mathrm{M}$ & $\mathrm{H}$ & $\mathrm{M}$ & Group $1^{\mathrm{h}}$ & Group $2^{\mathrm{h}}$ & Group $3^{\text {h }}$ \\
\hline$\overline{\mathrm{G} 1}$ & $1^{c}$ & 1 & 1 & 1 & 1 & 1 & 53 & 54 & 46 \\
\hline G2 & $0^{c}$ & 1 & 0 & 1 & 0 & 1 & 9 & 6 & 7 \\
\hline G3 & 1 & 0 & 1 & 0 & 1 & 0 & 16 & 4 & 10 \\
\hline G4 & $\mathrm{R}^{\mathrm{d}}$ & & $\mathrm{P}\left(\delta^{\pi}\right)^{\mathrm{e}}$ & & $P\left({ }^{\lambda}\right)^{e}$ & & 18 & 29 & 25 \\
\hline G5 & $\mathrm{P}(P)^{\mathrm{f}}$ & & $\mathrm{R}^{\mathrm{d}}$ & & $\mathrm{P}(\mathrm{P})^{\mathrm{f}}$ & & 11 & 13 & 20 \\
\hline D1 & 1 & 0 & 0 & 0 & 1 & 1 & 2 & 1 & 5 \\
\hline D2 & 0 & 1 & 0 & 1 & 1 & 1 & 0 & 0 & 12 \\
\hline I1 & 1 & 0 & 1 & 0 & 0 & 0 & 4 & 5 & 3 \\
\hline I2 & 0 & 1 & 0 & 1 & 0 & 0 & 3 & 4 & 3 \\
\hline I3 & 1 & 1 & 1 & 1 & 1 & 0 & 0 & 1 & 1 \\
\hline
\end{tabular}

${ }^{a}$ Only the major patterns are given: Class $\mathrm{G}=$ inherited pattern (i.e., the same methylation sites are found in both/ either parental lines and in their offspring); Class D = decreased methylation in offspring; Class I = increased methylation in offspring. ${ }^{b} \mathrm{H}$ and $\mathrm{M}$ are the combinations of enzymes of EcoRI/HpaII and $E c o \mathrm{RI} / M s p \mathrm{I}$, respectively. ${ }^{c} 1=$ methylation-sensitive amplified polymorphism (MSAP) band present; $0=$ MSAP band absent. ${ }^{\mathrm{d}}$ Random pattern allowed on this parent. ${ }^{\circ}$ Offspring showed same patterns as their sires. ${ }^{\mathrm{f}}$ Offspring showed same patterns as their dams. ${ }^{\mathrm{g}} \mathrm{No}$. of sites in the given group showing the respective methylation pattern of inheritance between parents and offspring. ${ }^{\mathrm{h}}$ Animal in Groups 1 and 2 are purebred parents and their offspring of White Leghorn (AA, Waalwijk and Flavell, 1978) and White Plymouth Rock (EE), respectively, while in Group 3, crossbred offspring were resulted from dam breed AA and sire breed EE.

\section{Sequence analysis of differentially methylated fragments between 2 parental lines and their offspring}

Based on the MSAP profile, same as the one in altered patterns described before, bands only observed in 2 parental lines or in one of their offspring were defined as differentially methylated fragments between parental lines and their offspring. Totally, 10 amplified fragments representing different methylation patterns were selected for further analysis; examples of partial patterns are shown in Figure 3. These specific methylated fragments were eluted from the silver-stained gel, re-amplified, and sequenced. Excised fragments from silverstained gels were further confirmed by methylation-sensitive Southern blot analysis with the isolated fragments as probes (see examples in Figure 3). Finally, 7 confirmed sequences were obtained and compared with the GenBank database using the BLASTn program. All of these 7 sequences had high similarity to characterized regions of the chicken genome, of which 4 sequences were located within the coding regions of genes, one in the 3 'downstream regions of genes, and the other 2 fragments in non-coding regions (details shown in Table 6).

More coincidentally, the homology of fragment I2-1 and I6-1 was up to $97 \%$ (Figure 4), while these 2 bands came from different groups (I2-1 detected in group 3, I6-1 in EE purebred, and absent in the AA purebred). According to Table 5, I2-1 was fully methylated in both parental lines, but more excessive methylation appeared in the offspring $\left(5^{\prime} \mathrm{C}^{\mathrm{m}} \mathrm{CGG}\right.$ 
$\rightarrow 5^{1 \mathrm{~m}} \mathrm{C}^{\mathrm{m}} \mathrm{CGG}$ ), and $\mathrm{I6}-1$ showed no methylation in the 2 parental lines but methylated at the external cytosine in the offspring $\left(5^{\prime} \mathrm{CCGG} \rightarrow 5^{\mathrm{Im}} \mathrm{CCGG}\right)$. Blasted against the GenBank database, fragment I2-1 and I6-1 were located on chromosomes 1, showed 100 and $99 \%$ similarity to the sequence in the third intron and the fourth exon of thyrotropin-releasing hormone degrading ectoenzyme gene from chicken, respectively, and the specifically methylated cytosine in $\mathrm{F}_{1}$ individual compared with 2 parental lines in the 2 fragments located in the exon area. On the other hand, the $5^{\prime}$ end and $3^{\prime}$ terminal of the sequence for I2-1 and I6-1 from groups 1 and 3 were AATTC and C, corresponding to the sequence of $\mathrm{G}$ of $5^{\prime} \mathrm{AATTC}$ adjacent and CGG of $3^{\prime} \mathrm{C}$ adjacent in GenBank, so the EcoRI recognition site of GAATTC and MspI/HpaII recognition site of CCGG by sequencing agreed with the digested product with $E c o \mathrm{RI} / M s p \mathrm{I}$, thus further confirming these 2 differentially methylated fragments.

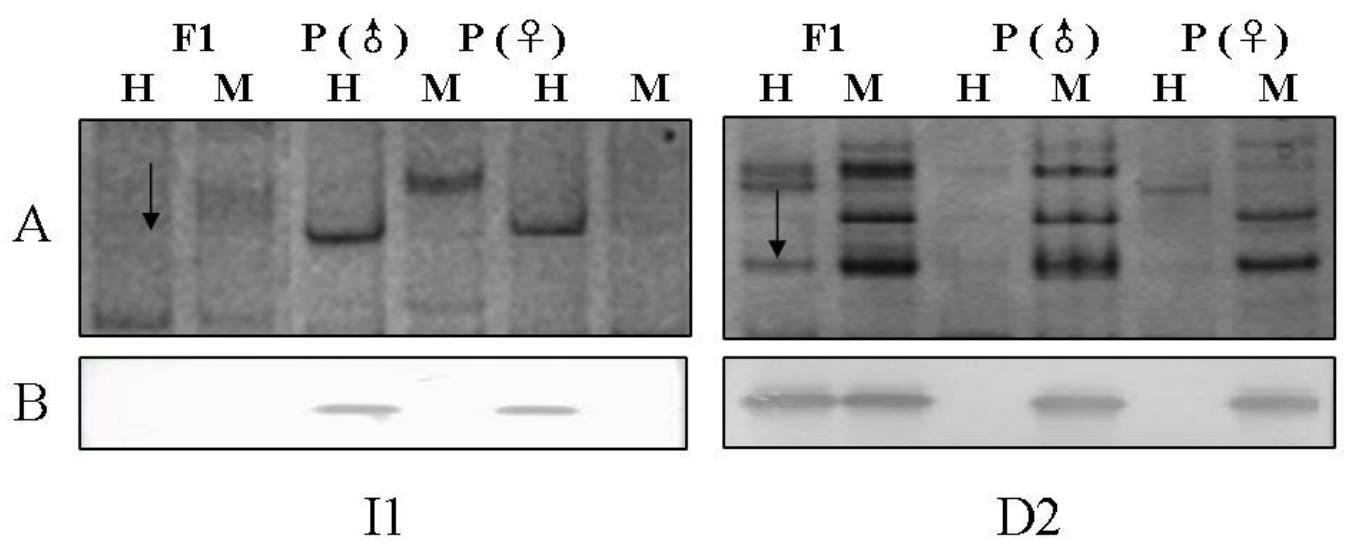

Figure 3. Examples of different methylation pattern between chicken parents and their offspring. I1 and D2 $=2$ different methylation patterns between chicken parents and their offspring, namely increased pattern type 1 and decreased pattern type 2. A. Different methylation patterns between chicken parents and their offspring tested by methylation-sensitive amplified polymorphism. B. Southern blot results to confirm the methylation pattern in A by the probe of $\mathrm{I} 1$ and D2, respectively. $\mathrm{H}$ and $\mathrm{M}=$ digestion with EcoRI/HpaII and EcoRI/MspI, respectively. Lanes $F 1, P\left(\delta^{\Uparrow}\right)$, and $P(+)=$ MSAP bands from $\mathrm{F} 1$ and their two parents.

Table 6. Sequence analysis of differentially methylated fragments in parental chicken lines and their offspring.

\begin{tabular}{lccclr}
\hline Fragment & Primer* E/H-M & Accession number & Chromosome location & Homologous gene & Homology \\
\hline D1-1 & AGA/TAC & NW_060420.1 & 9 & Glypican-5 precursor & $99 \%$ \\
D2-1 & ACA/TAC & NW_060265.1 & 2 & Non-coding region 3 & $100 \%$ \\
D5-2 & AGA/TAC & NW_060243.1 & 1 & Similar to ATM & $99 \%$ \\
I1-1 & AGA/TAC & NW_060527.1 & 14 & Non-coding region & $100 \%$ \\
I1-2 & AAG/TAC & NW_060426.1 & 9 & Non-coding region & $99 \%$ \\
I2-1 & ACA/TAC & NW_060207.1 & 1 & Similar to thyrotropin-releasing & hormone-degrading ectoenzyme \\
& & & 1 & Same to I2-1 & $99 \%$ \\
I6-1 & ACA/TAC & NW_060207.1 & $100 \%$ & 99 \\
\hline
\end{tabular}

*E/H-M $=$ core sequence of selective amplification is the same as in Table 2. 


\begin{tabular}{|c|c|c|}
\hline DNAMAN & I2-1 & G/AATTdACAT. CAAGAAAGAAAGGCCACAATGATAAAGCAGCATTCAGTGCTGTATACTTG \\
\hline DNAMAN & I6-1 & G/AATTGACATACAAGAAAGAAAGGCCACAATGATAAAGCAGCATTCAGTGCTGTATACTTG \\
\hline DNAMAN & I2-1 & TACTGTTACATTTGTTGTTGTT. . . AAACCACAAGAGTCAAGCGATGTCTTATTTACTAT \\
\hline DNAMAN & I6-1 & TACTGTTACATTTGTTGTTGTTGTTAAACCACAAGAGTCAAGCGATGTCTTATTTACTAT \\
\hline DNAMAN & I2-1 & GCCCATGAATAGTGCTGGTCACAGTCAGTAACTGCCGTGTTGGCTTTTGTCTGCTTCTTT \\
\hline DNAMAN & I6-1 & GCCCATGAATAGTGCTGGTCACAGTCAGTAACTGCCGTGTTGGCTTTTGTCTGCTTCTTT \\
\hline DNAMAN & I2-1 & TCTAGGTTTCTTGGTGTTACGCAGTTTTCTCCTACTCATGCCAGAAAAGCCTTTCCTTGC \\
\hline DNAMAN & I6-1 & TCTAGGTTTCTTGGTGTTACGCAGTTTTCTCCTACTCATGCCAGAAAAGCCTTTCCTTGC \\
\hline DNAMAN & I2-1 & TTTGATGAGCCCATCTACAAGGCCACTTTCAAAATCAGCATCAAGCATCAAGCAACTTAT \\
\hline DNAMAN & I6-1 & TTTGATGAGCCCATCTACAAGGCCACTTTCAAAATCAGCATCAAGCATCAAGCAACTTAT \\
\hline DNAMAN & I2-1 & ATATCTTTGTCCAACATGCCAGTTGAAACTTCTGTTTTTGAAGAAGATGGATGGGTTACA \\
\hline DNAMAN & I6-1 & ATATCTTTGTCCAACATGCCAGTTGAAACTTCTGTTTTTGAAGAAGATGGATGGGTTACA \\
\hline DNAMAN & $\mathrm{I} 2-1$ & GATCACTTTTCAGTACCGTCAAACCCCTCTCATGTCCACATATTACCTTGCTTGGGCAGT \\
\hline DNAMAN & I6-1 & GATCACTTTTCA. . . . . . CAAACCCCTCTCATGTCCACATATTACCTTGCTTGGGCAGT \\
\hline D. & $\mathrm{I} 2-1$ & GTGCAATTTTACGTA C/CCG \\
\hline DNAM & I6-1 & GTGCAATTTTACGTA C/CCG \\
\hline
\end{tabular}

Figure 4. Comparison between sequences of I2-1 and I6-1. G/AATTC = EcoRI site. G = Sequence in GenBanK. $\mathrm{C} / \mathrm{CCG}=$ Msp $\mathrm{I} / \mathrm{HpaII}$ site. $\mathrm{CCG}=$ sequence in GenBanK .

\section{DISCUSSION}

MSAP is a modified amplified fragment length polymorphism technique to investigate cytosine methylation in genomes. In brief, isoschizomers HpaII and MspI, recognizing the same sequences but differing in their sensitivity to methylation of their recognition site, are used instead of MseI to digest the genomic DNA, where methylation-sensitive polymorphic fragments can then be generated after PCR amplification with compatible adapters and primers. The specificities of HpaII and MspI are described in the REBASE database of restriction enzymes (McClelland et al., 1994). In summary, HpaII and MspI recognize the same sequence CCGG, but display different sensitivity to DNA methylation. The enzyme HpaII is sensitive to methylation of either cytosine residue at the recognition site (CCGG), whereas its isoschizomer $M s p$ I is sensitive only to methylation of the external cytosine. Therefore, methylation of the cytosine would lead to a different cleavage by these 2 isoschizomers and thus cause the different appearance of MSAP fragments (EcoRI-EcoRI, EcoRI-HpaII, EcoRI-MspI, $M s p \mathrm{I}-M s p \mathrm{I}$, and $H p a \mathrm{II}-H p a \mathrm{II})$ on the sequencing gel loaded with the amplification products from EcoRI/MspI and EcoRI/HpaII digestions. The bands EcoRI-HpaII or EcoRI-MspI are preferentially amplified compared with others. Now, MSAP is already extensively applied in many areas to explore the associations between methylation and plant phenotypic instability under various induced conditions (Aina et al., 2004; Labra et al., 2004), the abnormality of cultured plants (Li et al., 2002) and cloned animals (de Montera et al., 2004; Gao et al., 2011), 
performances of hybrids (Xiong et al., 1999; Madlung et al., 2002), and the comparison of methylation patterns in different tissues in animals such as swine and chickens (Xu et al., 2011; Yang et al., 2011). The results in the current study clearly demonstrate that MSAP is efficient for large-scale detection of cytosine methylation in the chicken genome and can be further extended to other animals or plants. However, it should be noted that MSAP is limited by the resolving power of this technique in the following respects. First, this method can only detect the methylation patterns of cytosines at the CCGG sites in the genome because the detection is restricted to the recognition sites of the isoschizomers used, such as $H p a \mathrm{II} / M s p \mathrm{I}$ in the present study. Second, as mentioned above, the enzyme HpaII is sensitive to methylation of either cytosine residue at the recognition site (CCGG), whereas its isoschizomer MspI is sensitive only to methylation of the external cytosine. Thus, the MSAP technique is unable to detect many other cytosine methylations in the restriction sites. Finally, the template DNA quality and length of sequencing gel may affect MSAP results.

Adapters and primers proposed by both Xu et al. (2000) and Xiong et al. (1999) were applied in the current study. Amplification was more efficient when adopting adapters and primers for HpaII-MspI digest fragments from the former authors, which confirmed the effectiveness of the improvement by Xu et al. (2000) in identifying methylated DNA profiles. Additionally, to yield distinct amplified fragments on the sequencing gel, we tested a large number of combinations of selective primers, with 3 selective nucleotides at the EcoRI end $(\mathrm{E}+3)$ and 1 to 4 selective nucleotides at the HpaII-MspI end $(\mathrm{HM}+1$ to $\mathrm{HM}+4)$. While other combinations either resulted in a smear or yielded too many amplified fragments to allow accurate detection, the primers for selective amplification were more efficient when using the combinations of $\mathrm{E}+3$ and $\mathrm{HM}+3$ in the current study, working on the chicken genome, compared to adding 4 nucleotides to their preamplification primers in experiments working on the plant genome (Xiong et al., 1999). This phenomenon may indicate that the methylation degree and the number of CCGG sites in chicken genome are different from those in the plant genome. Initially, we referred largely to the experimental conditions proposed by $\mathrm{Xu}$ et al. (2000), but changes were gradually made to pursue the best results considering the difference between the chicken and plant genome. Thus, it is recommended that one should refer to the related literature for prompt initiation, and establish one's own experimental system according to the specific objectives and experimental material for optimal results.

From the data in Table 4, the extent of cytosine methylation in the chicken blood genome was approximately $35 \%$, and the hemi-methylation of external cytosine was about $18.9 \%$, which occurred more frequently than full methylation in this study. Previously, we compared the levels of DNA cytosine methylation in 4 different tissues in chicken with MSAP. The results indicated that the degree of methylation was approximate $29.7 \%$ in muscle, $27.5 \%$ in liver, $27.5 \%$ in heart, and $26.1 \%$ in kidney, with less fully methylated sites than the hemimethylated sites in all 4 tissues examined (Xu et al., 2011). Combining results from these two studies, the average methylation level of the chicken genome is about $30 \%$, with different degrees of methylation of the genome in different tissues. These results are consistent with those reported in human (Grunau et al., 2000), rat (Song et al., 2005), rabbit (Waalwijk and Flavell, 1978), and rice (Xiong et al., 1999). The difference in DNA methylation level in various tissues is possibly related to the regulatory mechanism of gene expression during cell differentiation and development of chicken (Holliday and Pugh, 1975), although the function of methylation difference is complex and unknown to us. Additionally, the hemi-methylation sites (type 
III) occur more frequently than full-methylation sites (type II) in the chicken genome detected in these two studies, which appears very different from those of plants (Xu et al., 2000; Shaked et al., 2001; Madlung et al., 2002). This may be due to the difference in materials, and more indepth studies are warranted to confirm this difference between the plant and chicken genome.

The important role cytosine methylation plays in epigenetic regulation of gene expression has been well discussed because cytosine methylation can strongly influence gene expression, especially of the cytosine methylation alterations immediately upstream or downstream of gene. However, there are few reports on the molecular genetic basis of heterosis and cytosine methylation alterations in response to hybridization in domestic animals to date, because it is difficult to develop pure lines and large samples. In contrast, many studies in plants have found that heterosis is related to alterations in cytosine methylation (Xiong et al., 1998; Wang et al., 2010). From the comparison of methylation patterns across the 3 groups of animals in the current study, no difference in type III (hemi-methylation) level between parents and offspring in groups 1 (purebred AA, 20.3 vs 20.4\%, Table 4) and 2 (purebred EE, $17.95 \mathrm{vs} 18 \%$; Table 4) was found, but the hemi-methylation level of offspring (16.7\%) in group 3 (crossbred between AA dam and EE sire) was lower than that of their parents' average (19.4\%). Furthermore, in group 3, there was a higher frequency of sites with altered methylation patterns (18.2\%; Table 5) than that in groups $1(7.7 \%)$ and $2(9.4 \%)$, because animals in group 3 had more sites with D-type patterns (17 vs 2, and $17 v s$ 1). These findings indicate that decreased methylation had taken place at some sites of hybrids. Also, the increased or decreased methylation in the hybrid compared to the parents may provide an explanation for parent-specific and/or hybrid-specific differential gene expression as demonstrated in our previous studies (Sun et al., 2005). Accordingly, the MSAP technique may be a very useful tool to assess the degrees of DNA methylation in the genome of parents and their hybrids, to access the relationship of DNA methylation with heterosis. Moreover, those specific methylated fragments can be obtained and their methylation status can be confirmed by Southern analysis and sequencing, which can directly identify the sequences, and hence, the related genes that are differentially methylated between parents and their hybrids could be further researched.

\section{ACKNOWLEDGMENTS}

Research supported by the National Natural Scientific Foundation of China (\#31101711 and \#31172191), the Changjiang Scholar and Innovation Research Team in University (\#IRT1191), and the Natural Science Foundation of Beijing City, China (\#6112018).

\section{REFERENCES}

Aina R, Sgorbati S, Santagostino A, Labra M, et al. (2004). Specific hypomethylation of DNA is induced by heavy metals in white clover and industrial hemp. Physiol. Plant. 121: 472-480.

Bird AP and Taggart MH (1980). Variable patterns of total DNA and rDNA methylation in animals. Nucleic Acids Res. 8: 1485-1497.

de Montera B, Boulanger L, Taourit S, Renard JP, et al. (2004). Genetic identity of clones and methods to explore DNA. Cloning Stem Cells 6: 133-139.

Feng S, Jacobsen SE and Reik W (2010). Epigenetic reprogramming in plant and animal development. Science 330: 622627.

Gao F, Luo Y, Li S, Li J, et al. (2011). Comparison of gene expression and genome-wide DNA methylation profiling between phenotypically normal cloned pigs and conventionally bred controls. Plos One 6: e25901.

Gopalakrishnan S, Van Emburgh BO and Robertson KD (2008). DNA methylation in development and human disease. 
Mutat. Res. 647: 30-38.

Grazul-Bilska AT, Johnson ML, Borowicz PP, Minten M, et al. (2011). Placental development during early pregnancy in sheep: cell proliferation, global methylation, and angiogenesis in the fetal placenta. Reproduction 141: 529-540.

Grunau C, Hindermann W and Rosenthal A (2000). Large-scale methylation analysis of human genomic DNA reveals tissuespecific differences between the methylation profiles of genes and pseudogenes. Hum. Mol. Genet. 9: 2651-2663.

Herman JG, Graff JR, Myohanen S, Nelkin BD, et al. (1996). Methylation-specific PCR: a novel PCR assay for methylation status of CpG islands. Proc. Natl. Acad. Sci. U. S. A. 93: 9821-9826.

Holliday R and Pugh JE (1975). DNA modification mechanisms and gene activity during development. Science 187: 226-232.

Hyldig SM, Ostrup O, Vejlsted M and Thomsen PD (2011). Changes of DNA methylation level and spatial arrangement of primordial germ cells in embryonic day 15 to embryonic day 28 pig embryos. Biol. Reprod. 84: 1087-1093.

Keshet I, Schlesinger Y, Farkash S, Rand E, et al. (2006). Evidence for an instructive mechanism of de novo methylation in cancer cells. Nat. Genet. 38: 149-153.

Kurkjian C, Kummar S and Murgo AJ (2008). DNA methylation: its role in cancer development and therapy. Curr. Probl. Cancer 32: 187-235.

Labra M, Grassi F, Imazio S, Di FT, et al. (2004). Genetic and DNA-methylation changes induced by potassium dichromate in Brassica napus L. Chemosphere 54: 1049-1058.

Li XQ, Xu ML and Korban SS (2002). DNA methylation profiles differ between field- and in vitro-grown leaves of apple. J. Plant Physiol. 159: 1229-1234.

Li M, Wang T, Wu H, Zhang J, et al. (2012). Genome-wide DNA methylation changes between the superficial and deep backfat tissues of the pig. Int. J. Mol. Sci. 13: 7098-7108.

Madlung A, Masuelli RW, Watson B, Reynolds SH, et al. (2002). Remodeling of DNA methylation and phenotypic and transcriptional changes in synthetic Arabidopsis allotetraploids. Plant Physiol. 129: 733-746.

Mandel JL and Chambon P (1979). DNA methylation: organ specific variations in the methylation pattern within and around ovalbumin and other chicken genes. Nucleic Acids Res. 7: 2081-2103.

McClelland M, Nelson M and Raschke E (1994). Effect of site-specific modification on restriction endonucleases and DNA modification methyltransferases. Nucleic Acids Res. 22: 3640-3659.

Sato N, Fukushima N, Maitra A, Matsubayashi H, et al. (2003). Discovery of novel targets for aberrant methylation in pancreatic carcinoma using high-throughput microarrays. Cancer Res. 63: 3735-3742.

Shaked H, Kashkush K, Ozkan H, Feldman M, et al. (2001). Sequence elimination and cytosine methylation are rapid and reproducible responses of the genome to wide hybridization and allopolyploidy in wheat. Plant Cell 13: 1749-1759.

Shames DS, Minna JD and Gazdar AF (2007). Methods for detecting DNA methylation in tumors: from bench to bedside. Cancer Lett. 251: 187-198.

Song F, Smith JF, Kimura MT, Morrow AD, et al. (2005). Association of tissue-specific differentially methylated regions (TDMs) with differential gene expression. Proc. Natl. Acad. Sci. U. S. A. 102: 3336-3341.

Sun D, Wang D, Zhang Y, Yu Y, et al. (2005). Differential gene expression in liver of inbred chickens and their hybrid offspring. Anim. Genet. 36: 210-215.

Tost J, Dunker J and Gut IG (2003). Analysis and quantification of multiple methylation variable positions in CpG islands by Pyrosequencing. Biotechniques 35: 152-156.

Vanyushin BF (2005). Enzymatic DNA methylation is an epigenetic control for genetic functions of the cell. Biochemistry 70: 488-499.

Waalwijk C and Flavell RA (1978). DNA methylation at a CCGG sequence in the large intron of the rabbit beta-globin gene: tissue-specific variations. Nucleic Acids Res. 5: 4631-4634.

Wang H, Feng Q, Zhang M, Yang C, et al. (2010). Alteration of DNA methylation level and pattern in sorghum (Sorghum bicolor L.) pure-lines and inter-line F1 hybrids following low-dose laser irradiation. J. Photochem. Photobiol. B 99: 150-153.

Xiong L, Yang G, Xu C, Zhang Q, et al. (1998). Relationships of differential gene expression in leaves with heterosis and heterozygosity in a rice diallel cross. Mol. Breed. 4: 129-136.

Xiong LZ, Xu CG, Saghai Maroof MA and Zhang Q (1999). Patterns of cytosine methylation in an elite rice hybrid and its parental lines, detected by a methylation-sensitive amplification polymorphism technique. Mol. Gen. Genet. 261: 439-446.

Xu ML, Li XQ and Korban SS (2000). AFLP-based detection of DNA methylation. Plant Mol. Biol. Rep. 18: 361-368.

Xu Q, Zhang Y, Sun DX, Wang YC, et al. (2011). Analysis of DNA methylation in different chicken tissues with MSAP. Yi. Chuan 33: 620-626.

Yang C, Zhang M, Niu W, Yang R, et al. (2011). Analysis of DNA methylation in various swine tissues. Plos One 6: e16229. 